\title{
Parental influence on students' academic performance - A case study of Debre Berhan General Secondary School students, Debre Berhan, Ethiopia
}

\author{
${ }^{1 *}$ Wegayehu Enbeyle, ${ }^{2}$ Gebremedhin Desta, ${ }^{3}$ Digvijay Pandey \\ ${ }^{1}$ Department of Statistics, Mizan-Tepi University, Ethiopia. Email: wegayehu.info@gmail.com, \\ Phone: +251935604051 \\ ${ }^{2}$ Department of Statistics, Debre Berhan University, Ethiopia. Email: gmd202@gmail.com, \\ Phone: +251913963010 \\ ${ }^{3}$ Department of Technical Education, IET, Lucknow-226021, India. Email: \\ digit11011989@gmail.com, Phone: +91887454734
}

\begin{abstract}
Education plays an essential role in the acquisition of knowledge and skills. School is the place where children' attitudes, interests, and habits are developed. More involved and supportive a parent is towards their adolescent the higher self-esteem they will gain allowing the adolescent to feel confident and focused during school. Parents therefore enroll their children in schools that can give them expected quality of lives. The main core objective for this study was to determine the parental influence on students' academic performance - A case study of Debre Berhan General Secondary School. A total of 118 students were included in the present study using simple random sampling technique from the total students (2367). Cross-sectional design was appropriate for this study. Primary source of data was employed collected from students. Descriptive and inferential statistics were applied. For statistical analysis SPSS 20 was used at $5 \%$ level of significance. Descriptive statistics results indicate that the average mark of students was with minimum and maximum value of 47 and 94 respectively. Multiple regression models showed that Income level, Rate of money given to satisfy basic and educational materials, Parent's occupation, Family size, Parent's educational level, and Parent's way of giving motivation were found to be a significant effect on academic performance of students at $5 \%$ level of significance at study area. However, sex of students, age of students and grade level of students were not found to be significant effect to academic performance at study area. Overall model is statistically significance for the data. All the assumption of regression analysis was satisfied. Normality, Constant variance, absence of multicolinearity, linearity and absence of autocorrelation were satisfied due to formal tests and diagnostic plots. Study recommended the
\end{abstract}


need for programs related to improvement of mother and father education for caring child in appropriate success of their education and also parents should allocate time to visit schools and establish good relationship and discussion about their children's academic progress in according to way of motivation to learn actively in school.

Key words: Academic performance; Involvement of Parents, Debre Berhan General Secondary School, Ethiopia,

\section{Introduction}

Education is a primary need in this time of globalization[1], which plays an essential role in the acquisition of knowledge and skills. It is a powerful tool used by society for transmission of its societal values and to train the future generations inculcating them with skills and competencies [2-3]. In essence, parental involvement is the most influential factor which can promote higher achievement levels and educational success among students [4-5]. School is the place where children' attitudes, interests, and habits are developed [6], and these are some of the areas where parental involvement can benefit [7]. Factors including socioeconomic status, peers, teachers, faculty, or rigor of school are often influential on a child's academic success[8]. Therefore, parents shall prefer to enroll their children in schools that can give them expected quality life [9]. In view of this, academic performance would forever play an important role in producing the best quality graduates, who will become great leaders and manpower for the country, thus responsible for the countries socio-economic development. Academic performance of students is very much influenced by numerous factors like socioeconomic, status of the parents, residential locality of the students, gender, age, school and class room environment and many more.

Recent studies have shown that level of parental involvement can be a determining factor for the academic performance of a child [10-11]. In addition, academically less performing graduates will not be competitive in this competitive world and might not be able to contribute for the development of the country as intended; instead they can be a setback for the development of the country. This is a critical issue for secondary school students as well as for Ethiopia as a developing country.

Family has been identified as a critical force, even more powerful and direct influence compared to teachers in their children's education [12]. There may be associations(interaction) between 
involvement of parents, even just being around and supervising with academic performance vary according to the school level, gender, and the subjects [13-14]. Family that a child comes from either monogamous or polygamous family usually has impact on the child academic performance of students [15]. More involved and supportive a parent is towards their adolescent the higher self-esteem they will gain allowing the adolescent to feel confident and focused during school[16]. Debre Berhan secondary students confronted with many obstacles. Just as anyone else, they must overcome them in order to achieve their optimal academic performance. Thus, it takes a lot more than just classroom output to achieve a successful career. As a result, the failure rate of student is much greater in Debre Berhan town comparatively.

In general, academic performance in Debre Berhan secondary school was observed to be decreasing from time to time. Since, Ethiopia is a developing country; it should use its limited available resources effectively and efficiently. Parents, guardians and care givers must be encouraged to participate in their children's education keeping in view of the fact that graduating of unqualified students, not well skilled and incapable citizens is of little or no use for the country [17-20]. In this scenario, this study focuses on identifying factors influencing students' academic performance, so that adequate measures can be taken to deal with them. Specifically this study aimed to answer the following research questions with respect statistical data analyses: 1) Are there significant relationship and/or independents factors with (response variable) academic achievement? 2) To provide recommendations about parental influence on students' academic performance based on the findings of the study.

\section{Data and Methods}

This deals with detailed description about study area, source of data, study population, sampling technique, study variables, sample size determination and study design explanation about the theory behind the methods of and models for the analysis.

\subsection{Data source}

Data was collected from Debre Behan General Secondary School which was found in Debre Behan located in the North Shewa Zone, Amhara Region, Ethiopia. The study population were all $9^{\text {th }}$ and $10^{\text {th }}$ grade students in the school. We used primary data by designed questionnaire 
form students. Primary data refers to the data when researcher collects data directly from his observations and experience.

\subsection{Study Design}

For this study, cross sectional data collection method was done, which is appropriate when one or more than one variable are collected for several sample units at the same points in time. In this study, researcher collected the data from the students directly in a particular time.

\subsection{Sampling Technique}

In statistics, sampling is the word of expression getting sample from the total population. The target populations for this study students' entire grade $9^{\text {th }}$ and $10^{\text {th }}(2367)$. Before actual data collection; we must do on the sample size determination of the population based on the nature of data types. In this study, simple random sampling (a probabilistic sampling) technique was applied for getting the target sample from the population (total of students in the school).

\subsection{Sample size Determination}

Sample size was calculated using a single population proportion formula using the following parameters: confidence level, the margin of error, and maximum variation will be expected. Then where the required sample size is a $95 \%$ confidence level for normal distribution which is 1.96 , is a margin of error (5\%). In order to get desired sample size we use the formula. The sample size was calculated as

$$
n_{o}=\frac{\left(Z_{a / 2}\right)^{2} S^{2}}{e^{2}}=\frac{(1.96)^{2} * 0.769}{0.0025}=118
$$

Where; $\boldsymbol{Z}_{\boldsymbol{a} / \mathbf{2}}$ is level of significance, $\boldsymbol{S}^{\mathbf{2}}$ is estimated variances for 20 students by asking the response variable (what is your average mark in the academic year) by conduct pilot survey and $\boldsymbol{e}$ is margin of error.

\subsection{Study Variables}

The dependent variable for this study was average mark of the students scored in first semester. The explanatory variables are based on literature reviews of different studies. The independent variables are measured from structural questionnaires and these are related to socio-demographic and economic factors. Therefore, the independent variables included in this study were list out below Table 1. 
Table 1. Independent variables included in the present study

\begin{tabular}{|l|l|}
\hline Variables & Coding(Categories) \\
\hline Sex & {$[0=$ Male, $1=$ Female $]$} \\
\hline Age & {$[$ Continuous $]$} \\
\hline Grade level & {$\left[0=9^{\text {th }}, 1=10^{\text {th }}\right]$} \\
\hline Mother Educational level & {$[0=$ Illiterate, $1=$ Elementary \& Secondary, $2=$ Above College level $]$} \\
\hline Father Educational level & {$[0=$ Illiterate, $1=$ Elementary \& Secondary,2= Above College level $]$} \\
\hline Mother Occupation & {$[0=$ Farmer, $1=$ Employee, $2=$ Merchant, $3=$ Other $]$} \\
\hline Father Occupation & {$[0=$ Farmer, $1=$ Employee, $2=$ Merchant, $3=$ Other $]$} \\
\hline Family size & {$[$ Continuous $]$} \\
\hline Rate of money given to students & {$[0=$ Insuffiecnt, $1=$ Suffiecnt $]$} \\
\hline Way of giving motivation to students & {$[0=$ By rewarding, $1=$ By enforcing,, $2=$ By advising,, $3=$ Other $]$} \\
\hline Family's income per month in birr & {$[$ Continuous $]$} \\
\hline
\end{tabular}

\subsection{Statistical Data Analysis}

\subsubsection{Descriptive statistics}

Descriptive statistics consists of the collection, organization, summarization, and presentation of data. In descriptive statistics the statistician tries to describe a situation. Once data is collected, the researcher must organize and summarize them. Finally, the researcher needs a means of presenting the data in some meaningful form, such as charts, graphs, or tables.

\subsubsection{Multiple linear regression model(MLR)}

Multiple linear regression models are used to model the relationship between a single dependent variable (response variable) and more than one independent variable. Multiple linear regression is required so that the dependent variable to be continuous and the independent variable to be discrete, continuous and categorical. In the model of multiple linear regressions, response variable is a linear function of the $\mathrm{k}$ explanatory variables and of a statistical error term. The model also has an intercept. Designating the single response variable by $\mathrm{Y}$, the $\mathrm{K}$ independent variable by $\mathrm{X} 1, \mathrm{X} 2, \mathrm{X} 3 \ldots \mathrm{Xk}$ and the error term bye, the population model of multiple linear regression is given by the following expression:

The model is denoted by: 


$$
\mathrm{Y}=\beta_{0}+\beta_{1} \mathrm{X}_{1}+\cdots \ldots+\beta_{\mathrm{k}} \mathrm{X}_{\mathrm{k}}+\varepsilon
$$

Where;

○ $Y$ is response variable(average mark of students)

- $\beta_{0}$ is constant parameter

$\circ \beta_{1}, \ldots \ldots \beta_{k}$, are unknown parameters. $i=1,2 \ldots k$

○ $X_{1}, X_{2} \ldots \ldots X_{k}$, were explanatory variables

$\circ \varepsilon$ is the error term

The model parameters were estimated by using least square estimation method in order estimate the unknown parameter for multiple linear regressions. The ordinary least square estimation can be work as after a certain procedures.

$$
\widehat{\beta}=\left(x^{\prime} x\right)^{-1} x^{\prime} y
$$

Where; $y$ is vector of observation of academic achievement, $y(n x p)$ is invertible matrix of coefficient, $y$ is matrix of factors affecting the academic achievement, $\beta$ s are vectors of the coefficients of the regresses (independent) and $\beta(\mathrm{px} 1)$ is vectors of regression that was estimated from the data.

\subsubsection{Assumption regression model}

Multiple regression models should be linear and also parameter should enter the model in linear form (Linearity)

$>$ Errors have normal distribution with mean vector zero(Normality)

$>$ Variance of the errors at each fixed values of the independent variables is constant that is $\delta^{2}$ (Homoskedasticity)

$>$ There is no correlation between successive error terms. That is $\operatorname{corr}(\varepsilon i, \varepsilon j=0$ ) (non autocorrelation). Autocorrelation occurs when the residuals are not independent from each other.

$>$ There must not be significant relation between the independent variables in other words $\mathrm{X}$ is a $\mathrm{n} \times \mathrm{k}$ matrix of full rank (no Multicolinerity). It occurs when several independent variables correlate at high levels with one another.

\subsubsection{Hypothesis testing for ANOVA}


Adequacy of the model in multiple linear regressions can be checked by testing the regression coefficient associated with the independent variable.

Step 1: Identify the null and alternative of hypothesis:

Ho: $\beta 1=\beta 2=\beta 3=\cdots \beta \mathrm{k}=0$ (the model is not adequate to fit the data)

Ha: $\beta \mathrm{i} \neq 0$ for at least one $\mathrm{i}=1,2,3, \ldots \mathrm{k}$ (the model is adequate to fit the data)

Step 2: Fix the level of significance and the tabulated value:

$$
\alpha=0.05 \text { (most of the time) }
$$

Step 3: Find the test statistic

$$
\mathrm{F} \text { cal }=\frac{\mathrm{MSR}}{\mathrm{MSE}}
$$

Where,

$$
\begin{gathered}
\text { MSR }=\frac{\text { SSR }}{d f}=\frac{S S R}{(k+1)-1} \\
\text { MSE }=\frac{\text { SSres }}{d f}=\frac{\text { SSres }}{n-(K+1)}
\end{gathered}
$$

Step 4: Decision and rejection region:

Decion rule reject Ho if, $\mathrm{f}$ cal $>f t a b$

Step 5: Conclusion:

Rejecting the null hypothesis implies that the adequacy of the model to fit the data very well.

\subsubsection{Hypothesis testing on the individual regression coefficient}

In case, if the test in analysis of variance is rejected, then another question arises is that which of the regression coefficients is/are responsible for the rejection of null hypothesis. The explanatory variables corresponding to such regression coefficients are important for the model.

Step1: State the null and alternative hypothesis

Ho: $\beta \mathrm{i}=0$ (the $\mathrm{i}^{\text {th }}$ predictor has not significant contribution to the model)

$\mathrm{Ha}: \beta \mathrm{i} \neq 0$ (the $\mathrm{i}^{\text {th }}$ predictor has significant contribution to the model)

Step 2: Fix the level of significance ( $\alpha$ value) and find the tabulated value:

Since it is two tailed hypothesis the tabulated value will be $\mathrm{t} t a b=\mathrm{t} \frac{\mathrm{a}}{2}^{(\mathrm{n}-(\mathrm{k}+1)}$

Step 3: Compute the test statistic

The test statistic which has been used to test the above hypothesis is $\mathrm{tcal}=\frac{\mathrm{bi}}{\widehat{\delta} \sqrt{\mathrm{Cii}}}$ and has a $\mathrm{t}$ distribution with $\mathrm{n}-(\mathrm{k}+1)$ degree of freedom) under the null hypothesis

Step 4:Find the rejection region and make your decision: 
Calculated value will be compared to the tabulated value and if the calculated value is greater than the $\mathrm{t}$-tab or if it is less than negative of the tabulated value, null hypothesis will be rejected. Rejecting the null hypothesis implies that $i^{\text {th }}$ independent variable has statistically significant contribution to the model.

Step 5: Make conclusion

\section{Results}

The main core objective of this study was to identifying the factors the influence of parent's on academic performance of students. Both descriptive and multiple linear regressions were used to identify the factors for explaining academic achievement of students in case of study area. For statistical analysis SPSS version 20 software was used at 5\% level of significance. Study revealed the average mark of students was with minimum value of 47 and maximum value of 94 respectively.

Table 2. revealed that 0.861 shows the model is adequate (good fitted the data), implies that $86 \%$ of the variability in the average mark of student are explained by the variability of the independent variables in the estimated regression and while $14 \%$ explained by other nonexplained factors out of our determined independent variable in the study. From Table 2. Durbin Watson test revealed that absence of autocorrelation for the assumption of multiple linear regressions. Errors must be uncorrelated.

Table 2. Model summary statistics of the study

\begin{tabular}{|l|l|l|l|l|l|}
\hline \multirow{2}{*}{ Model } & R & R Square & Adjusted R Square & Std. Error of the Estimate & Durbin Watson test \\
\cline { 2 - 6 } & 0.937 & 0.879 & 0.861 & 4.93 & 1.295 \\
\hline
\end{tabular}

Table 3 results shows that the p-value (.000) reveled that combination of variables significantly affect and predicts the dependent variable (average mark of students).

Based on the analysis of variance tables we have to test the overall test of the regression model. From the ANOVA tables Table 3. P-value $(.000)<0.05$, therefore, we can conclude that at $5 \%$ level of significance at least one of the $\beta_{j}$ has significance impact on the regression model. The overall model is statistically significance for the data. 
Table 3. ANOVA summary table

\begin{tabular}{|l|l|l|l|l|l|}
\hline Model & Sum of Squares(SSE) & Degree of freedom(DF) & Mean Square(MSE) & Fcal & (P-value) \\
\hline Regression & 17968.08 & 15 & 1197.87 & 49.31 & .000 \\
\hline Residual & 2477.680 & 102 & 24.29 & & \\
\hline Total & 20445.76 & 117 & & \\
\hline
\end{tabular}

The final fitted regression model given from Table 4.

Average mark of students

$$
=86.48-4.67 \text { Sufficient }+0.001 \text { Average income of family per month }
$$

- 2.39Family size + 5.76By enforcing - 6.12M. edu Above Collage

- 3.87F. edu Above Collage - 2.73M. occ Merchant - 2.85F. occ Employee

Table 4. Coefficient table

\begin{tabular}{|c|c|c|c|c|c|}
\hline \multirow[t]{2}{*}{ Model } & \multirow[t]{2}{*}{ Categories } & \multicolumn{2}{|c|}{$\begin{array}{l}\text { Unstandardized } \\
\text { Coefficients }\end{array}$} & \multirow[t]{2}{*}{ t-test } & \multirow[t]{2}{*}{ P-value) } \\
\hline & & Beta & Std. Error & & \\
\hline$\beta_{0}($ Constant $)$ & \multicolumn{2}{|l|}{86.48} & 4.83 & 17.92 & .000 \\
\hline $\begin{array}{l}\text { Rate of money given to students[Ref= } \\
\text { Insufficient] }\end{array}$ & Sufficient & -4.67 & 1.67 & -2.8 & $.006 *$ \\
\hline Average income of family per month & & .001 & 0.001 & 1.67 & $.024^{*}$ \\
\hline Family size & & -2.39 & 0.41 & -5.83 & $.000 *$ \\
\hline \multirow[t]{3}{*}{ Way of giving motivation [Ref=By advising] } & By enforcing & 5.76 & 1.62 & 3.55 & $.001 *$ \\
\hline & By rewarding & -2.63 & 1.68 & -1.56 & .122 \\
\hline & By other method & 6.79 & 2.30 & 2.95 & .051 \\
\hline \multirow[t]{2}{*}{ Mothers education [Ref=Illiterate] } & Above Collage & -6.12 & 2.20 & -2.79 & $.006 *$ \\
\hline & $\begin{array}{l}\text { Elementary \& } \\
\text { Secondary }\end{array}$ & -1.45 & 1.11 & -1.31 & .194 \\
\hline \multirow[t]{2}{*}{ Fathers education [Ref=Illiterate] } & $\begin{array}{l}\text { Elementary \& } \\
\text { Secondary }\end{array}$ & 2.15 & 1.29 & 1.66 & .100 \\
\hline & Above Collage & -3.87 & 1.47 & -2.63 & $.010 *$ \\
\hline \multirow[t]{3}{*}{ Mothers occupation[Ref $=$ Farmer] } & Merchant & -2.73 & 0.99 & -2.75 & $.007 *$ \\
\hline & Employee & .370 & 1.36 & .27 & .790 \\
\hline & Other & -2.9 & 1.81 & -1.65 & .100 \\
\hline \multirow[t]{3}{*}{ Fathers occupation $[\operatorname{Ref}=$ Other $]$} & Employee & -2.85 & 1.45 & -1.98 & $.025 *$ \\
\hline & Farmer & .910 & 1.62 & .56 & .580 \\
\hline & Merchant & -0.42 & 0.35 & 1.23 & .233 \\
\hline
\end{tabular}

*=Statistically significant at 5\%

Table 4. results reveled that Mother Educational level, Father Educational level, Mother Occupation, Father Occupation, Family size, Rate of money given to respondent, Way of giving 
motivation to students, Family's income per month in birr and Parents follow up their children's were statistically significant effect on academic achievement $5 \%$.

Rate of money given to students to satisfy basic and education materials had significant effect of academic achievement of students. Students who had enough basic needs for educational works more satisfied and more competent. Table 4. $\beta=-4.667$ shows that student who had enough rate of income given from their parents have good academic performance compared to that of the references category(No) assuming all predictors variables are constant. Parents' income level influences their capacity to contribute towards their children's education. It determines the amount of resources parents can devote to their children's school related needs.

Average income of family per month also an important factor academic achievements of students. Students whose parents were richer students being educated one. Table 4. $\beta=.001$ shows that as per unit change in family income per month the average mark of student's increase by the amount of 0.001 assuming others were constant. Children of low-income parents do not perform well and more likely to repeat a grade and to drop out school than children of middle and upper income families. This implies that the higher the family income the better will be the students' academic results.

Family size had significant effect on academic achievements of students. Table 4. $\beta=-2.39$ shows that when family size increase by one unit(number) in house the academic performance of students decreased by 2.39 assuming others were constant. Academic achievement among children dropped as family size grew, because parents had less time and resources for each child. As a result more children in a household mean less attention and less effective economic support for each child. Even if family in a large, there is a great inequality in education need for girl's labor at home. Consequently, they lack time to do their homework, assignments, study and discussion time with peers. Finally, boys from large family tend to have a better academic achievement than girls.

Another predictor variable's what we call it education of parents also had effect on students' academic performance. Additionally, parents' education also had factor affecting achievement of students. Parents' education has very great effect on the overall activities of the students in the school. Table 4. $\beta=-6.12$ show that students whose mother education was collage level more 
accessing of education performed compared to that of the references. Table $4 . \quad \beta=-3.87$ also show that students whose father education was collage more performance in academic competent compared to that of others. Literate and illiterate families do not help their children equally in their education. Educational background of parents' highly contributes for the success or failure of students. In fact well-educated parents can be involved in school matters and understand the value of education or academic performances.

Way of giving motivation for students' academic achievement at school also good indicator of education. Students whose parent's motivate with their children or sons by enforced from Table 4. $\beta=-5.76$ less academic performance than that of advising and rewarding. Advising children was good way method of enhancing achievement or performance at school or school out. Children's capability was more advanced to succeed in school depends on how successfully they are managed by their parents in the home environment by the way of motivation by advising rather than enforcing.

Parent's occupation had factor that affect performance of students. Table 4. $\beta=-2.734$ and $\beta=-$ 2.854 shows that parameters of mothers occupation (merchant) and fathers occupation (Employee) respectively. Students whose mothers who had merchant were less than academic performance compered to others. Students whose fathers who had employee were more than academic performance compered to others. Students from high-level occupation are more likely to have the economic resources to purchase instructional materials and educational service (example, computers, and tutors-tuitions) that are not available to students whose parents have low-level occupational status. Students whose parents were professional occupations were found to have higher achievement than others. In other words, students whose parents had occupations those specifically required strong in skills that are physical mathematical and engineering science professionals tended to have highest mathematical scores than other students. Generally, parental occupational status is strongly associated with how people think about and act in school.

After fitted the model one important point to keep in mind is that these assumptions are for the population and we work only with a sample. So the main issue is to take a decision about the population on the basis of a sample of data. Several diagnostic methods to check the violation of 
regression assumption are based on the study of model residuals with the help of various types of graphics.

\section{Normality}

Normality assumption usually checked by histogram. Fig 1 displayed that the residual of the average mark students was normally distribution with mean 0 and variance 1 (dependent variable normally and independently distribution with mean $\left(-7.64 * 10^{-15} \approx 0\right)$ and variance $(0.934 \approx$ 1) and it indicate that residual approximately normally distributed with $\mu \sim(0,1)$. As result of the normality was satisfied. Data satisfied normality assumption (see Fig 1).

Histogram

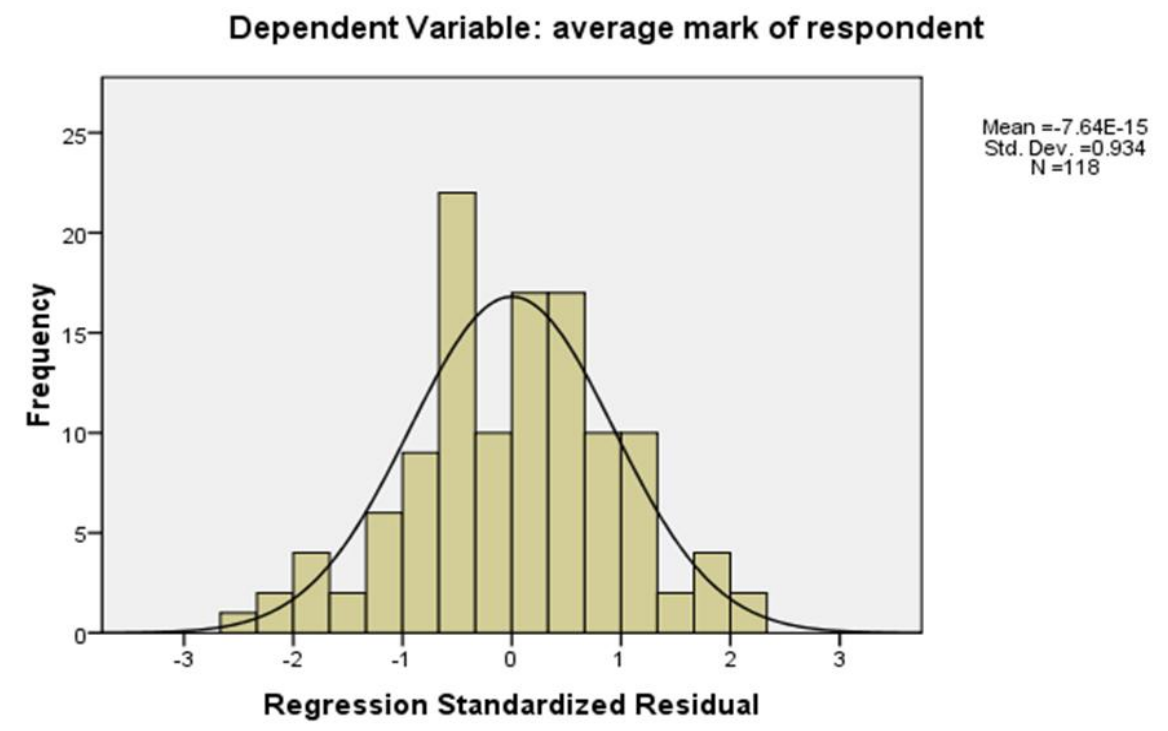

Figure 1. Histogram plot in bar chart depicting the normality assumption

\section{Linearity}

One detection method assumption of linearity is that Normal Probability Plot (NPP). A statistician, one can conclude that from Fig 2 the model becomes normal. The plots of the ordered standardized residuals are approximately the same as the ordered normal scores. Under normality assumption, the plot indicates nearly straight line with an intercept of zero and a slope of one (these are the mean and standard deviation of residuals respectively). Generally, the linearity and normality assumptions are satisfied (Fig 2.). 


\section{Normal P-P Plot of Regression Standardized Residual}

\section{Dependent Variable: average mark of respondent}

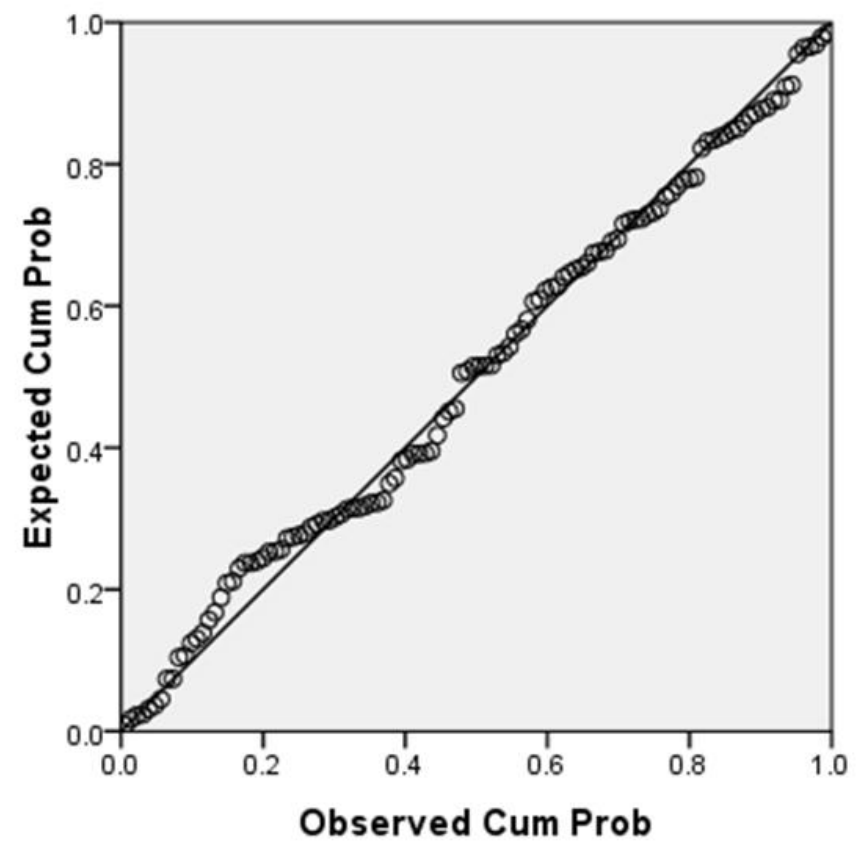

Figure 2. Normality probability plot: $\mathrm{X}$-axis represents the observed and Y-axis represents the expected prob.

\section{Constant Variance}

Good way of detection of when constant variance assumption satisfied or not is that residuals vs. fitted values. From Fig 3 plots were random scatter of points (it is not in systematic pattern). This shows that the standardized residual are uncorrelated with the fitted value. Therefore, the plot is random or non-systematic pattern there is no problem constant variance in the model (see Fig 3.). 


\section{Dependent Variable: average mark of respondent}

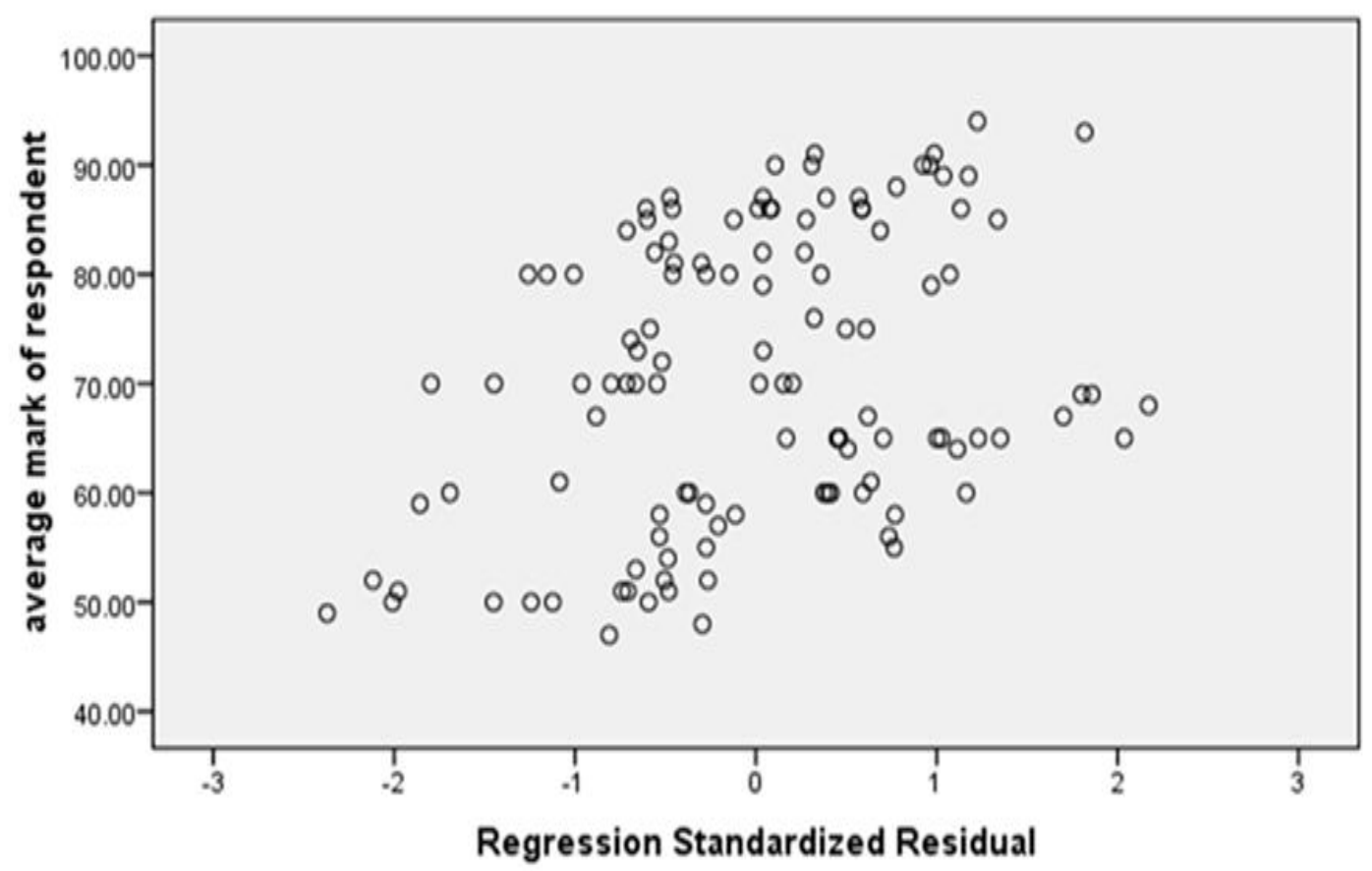

Figure 3. Scatter plot: $\mathrm{X}$-axis represents the regression standardized residual and $\mathrm{Y}$-axis represents the average mark of respondent.

\section{Multicolinearity}

In regression analysis basically absence of Multicolinearity can be checked by VIF (Variance Inflation Factor). When the value VIF for each predictor variables were less than 10 we can conclude that absence of Multicolinearity.

Table 5 summarized that there is absence of Multicolinearity. VIF for each continuous predictor variables were less than 10 (see Table 5.). Model is good fitted.

Table 5. Collinarity Diagnostics for the model average income of family per month and family size.

\begin{tabular}{|l|c|c|}
\hline Model & \multicolumn{2}{|c|}{ Collinarity diagnostics } \\
\cline { 2 - 3 } & Tolerance & VIF \\
\hline Average income of family per month & .365 & 2.743 \\
\hline Family size & .251 & 3.985 \\
\hline
\end{tabular}




\section{Conclusion}

The study focused on analyzing of influence on academic performance among Debre Berhan secondary school students. Descriptive and Multiple linear regression statistical model analyses were applied to identify the predictors for academic achievement of students. Frequency table result reveled that for current study the average mark of students of students was with minimum value and maximum value of 47 and 94 respectively. According to the results of multiple regression analysis, Income level, rate of money given to satisfy basic and educational materials, Parents occupation, family size, Parents educational level, and Parents way of giving motivation were significantly effect at $5 \%$ level of significance (see Table 4). However, sex of students, age of students and grade level of students were not found to be significant effect to academic performance (see Table 4). Obtained multiple coefficient of determination indicates that there were over all relationship. F-test also revealed that this proportion of variance is statistically significant. The overall model is statistically significance for the data (see Table 3.). All the assumption of regression analysis was satisfied. Normality, Constant variance, absence of Multicolinearity, linearity and absence of autocorrelation were satisfied due to formal tests and diagnostic plots (see Fig 1. Fig 2. Fig 3. Table 5.).

\section{Recommendations}

After gathering data, analyzing, and interpreting it, the following recommendations were forwarded.

$\checkmark$ It is advisable for parents to improve their income level per month by involving in various different activities that help them generate additional income, to increase the rate of money given to basic and educational materials for students in academic achievement.

$\checkmark$ The study recommended the need for programs related to improvement of mother and husband education for caring child in appropriate success for their education.

$\checkmark$ Since schools are the integral part of teachers, students and parents, parents should allocate time to visit schools and establish good relationship and discussion about their children's academic progress in according to way of motivation to learn actively in school.

$\checkmark$ It is advisable for schools to have a well-organized students' record including the parent's income per month, educational level, occupation status, family size and others that help them identify easily when support is available for academic achievement. 


\section{References}

1. N. A. Bakar, I. Mamat, and M. Ibrahim, "Influence of Parental Education on Academic Performance of Secondary School Students in Kuala Terengganu," vol. 7, no. 8, pp. 296304.

2. Id, "The Influence of Parents' Educational Background on the Academic Achievement of the Government High School Students in," vol. 2751.

3. S. T. Ebong, "The influence of parental background on students' academic performance in physics in WASSCE 2000 - 2005," vol. 3, no. 1, pp. 33-44, 2015.

4. D. R. Antoine, "The Correlation Between Parental Involvement and Student Academic Achievement," 2015.

5. E. C. Development and C. H. Descartes, "Parental influence on academic achievement among the primary school students in Trinidad," 2016.

6. S. Hussain, Z. Javaid, S. Parveen, and A. Iqbal, "Relationship between Parental Involvement and Students 'Performance in Secondary Schools," vol. 7, no. 3, pp. 203-209, 2007.

7. P. Johnson, "Types of Parental Involvement and Their Effect on Student Mathematics in Secondary Education: Attitudes , Self-Efficacy , and Achievement," 2016.

8. M. Jurado, "Parental Involvement Impacting Student Academic Success in AVID," vol. 4, no. 2, 2014.

9. A. Oa and S. Dosunmu, "Significance of Parental Influence on School Growth and Population in African Contexts," vol. 9, no. 4.

10. O. O. Oyedare, O. O. Ogunjinmi, and A. M. Durojaiye, "Parental Involvement As A Determinant Of Students' Academic Performance In Agricultural Science In Selected Secondary Schools In Oyo Metropolis , Oyo State,” vol. 2, no. 2, pp. 17-22, 2016.

11. L. Lara, M. Saracostti, Y. R. Harris, and A. P. Goldin, "Effect of Parental Involvement on Children's Academic Achievement in,” vol. 10, pp. 1-5, 1987.

12. F. Length, "A study of adolescents ' perception of parental influence on academic activities," vol. 5, no. 4, pp. 66-71, 2013.

13. O. D. Paper, I. P. Policy, P. Involvement, and J. E. L. Codes, "Relationships between Parental Involvement and Academic Achievement among Elementary and Middle School Students Midori Otani," pp. 1-31.

14. R. P. Principal and D. Y. P. College, "A Study of the Impact of Educational Qualifications of Parents on the Academic Performance of students of class XI in English Medium CBSE schools in PCMC area Introduction:," vol. 1, no. 1, pp. 15-20.

15. R. N. R. M. Rnt, M. Ed, and D. Ph, "Influence of Family Size and Family Type on Academic Performance of Students in Government in Calabar Municipality, Cross River State , Nigeria," vol. 2, no. 11, pp. 108-114, 2015.

16. J. Schmuck, "Parental Influence on Adolescent's Academic Performance," vol. 9, 2011.

17. V. J. Shute, E. G. Hansen, J. S. Underwood, and R. Razzouk, "A Review of the Relationship between Parental Involvement and Secondary School Students 'Academic Achievement," vol. 2011, 2011. 
18. B. E. Sub-county, "Analysis of Family Structure Influence on Academic Performance Among Secondary School Students in,” vol. 4, no. 2, pp. 12-22, 2016.

19. S. Talluri and M. E. Suneela, "Impact of parental involvement on academic achievement of secondary school students," vol. 2, no. 5, pp. 180-183, 2013.

20. L. V. Washington, "The Effects of Parent Involvement on Student Outcomes in a MinorityServing Charter High School," 2016. 